\title{
Fabrication of Electrochemical Sensor for Acetaminophen Based on Levodopa Polymer and Multi-walled Carbon Nanotubes Complex
}

\author{
Hui Yang ${ }^{1, *}$, Zhiqiang $\mathrm{Wei}^{1}$, Suna $\mathrm{He}^{1}$, Tian $\mathrm{Li}^{1}$, Yanfeng $\mathrm{Zhu}^{2}$, Lengxin Duan ${ }^{1}$, Yan $\mathrm{Li}^{1, *}$, \\ Jiangang Wang ${ }^{1, *}$ \\ ${ }^{1}$ Department of pharmacy, Collage of Medical, Henan University of Science and Technology, \\ Luoyang, 471023, China. \\ ${ }^{2}$ School of Materials Science and Engineering, Henan University of Science and Technology, \\ Luoyang, 471023, China. \\ *E-mail: yanghui7761@ 163.com, lyhkdly@163.com, ylwjg@163.com
}

doi: $10.20964 / 2017.12 .50$

Received: 31 August 2017 / Accepted: 6 October 2017 / Published: 12 November 2017

In this work, we describe the fabrication of electrochemical sensor for acetaminophen (ACOP) based on levodopa (L-Dopa) polymer and multi-walled carbon nanotubes (MWCNTs) complex modified carbon paste electrode (Poly (L-Dopa)/MWCNTs/CPE). L-Dopa Polymer and MWCNTs complex is prepared by in situ electrochemical polymeric deposition and the electrochemical polymeric deposition behavior of L-Dopa on the surface of MWCNTs was investigated by cyclic voltammetry (CV). A novel method for the determination of ACOP is developed based on a well-defined electrochemical response signal of ACOP at Poly (L-Dopa)/MWCNTs/CPE by differential pulse voltammetry (DPV). Under the optimized conditions, the value of the DPV oxidation peak current linearly depends on the concentration of ACOP in the range from 0.06 to $30 \mu \mathrm{M}$. The linear equation for ACOP detection is $\mathrm{I}_{\mathrm{pa}}$ $(\mu \mathrm{A})=0.0718 \mathrm{c}(\mu \mathrm{M})+0.0307(\mathrm{r}=0.9990)$ and the detection limit is $0.02 \mu \mathrm{M}(\mathrm{S} / \mathrm{N}=3)$. The recoveries for ACOP are from $98.2 \%$ to $99.4 \%$ with relative standard deviation (RSD) between $3.9 \%$ and $4.6 \%$ in diluted serum samples.

Keywords: Acetaminophen; Levodopa; Multi-walled carbon nanotubes; Electrochemical polymeric deposition; Electrochemical sensor.

\section{$\underline{\text { FULL TEXT }}$}

(C) 2017 The Authors. Published by ESG (www.electrochemsci.org). This article is an open access article distributed under the terms and conditions of the Creative Commons Attribution license (http://creativecommons.org/licenses/by/4.0/). 